\title{
DE LA MATERIA A LA PALABRA: LA INTERRELACIÓN ENTRE LA ANTROPOLOGÍA Y LA TRADUCCIÓN EN LA PRODUCCIÓN DE JOSÉ MARÍA ARGUEDAS
}

\author{
Roseli Barros Cunha \\ Universidade Federal do Ceará \\ roselibc@gmail.com
}

Resumen: J. M. Arguedas recogió leyendas y mitos provenientes de la cultura inca y tradujo algunos de esos textos para el español. Además de eso, en su producción literaria insertaba de diversas formas las informaciones recogidas y recurría a algunos procedimientos traductológicos con la finalidad de llevar a su lector el conocimiento de la cosmovisión de una cultura transculturada. Verificaré en algunas de sus obras y ensayos antropológicos de qué modo se produce esa intersección entre antropología, traducción, literaturas orales y escritas como formas de acercamiento a la cultura del otro. El autor peruano en su última novela, El zorro de arriba y el zorro de abajo, cuenta que cuando encontraba "tono de vida" podía "transmitir a la palabra la materia de las cosas". Eso demuestra que la lengua utilizada por Arguedas, sea para traducir las leyendas indígenas o para escribir sus textos literarios, tiene importancia como vehículo de expresión de la cosmovisión heterogénea que se acentúa a lo largo de su obra culminando con la experiencia herviente encontrada en Chimbote.

Palabras-clave: Traducción, Antropología, América Latina.

\section{FROM MATTER TO THE WORD: THE INTERRELATION BETWEEN ANTHROPOLOGY AND TRANSLATION IN THE WORK OF JOSÉ MARÍA ARGUEDAS}

Abstract: J.M. Arguedas collected legends and myths from Inca culture and translated some of these texts for Spanish. Moreover, in his literary 
production inserted in various ways the information collected and resorted to some translation strategies in order to lead his reader with the knowledge of the worldview of a transculturated culture. I will verify some of his works and essays anthropological how that intersection occurs between anthropology, translation, oral and written literature as ways to approach the other's culture. The Peruvian author in his latest novel, El zorro de arriba y el zorro de abajo, says that when he found "tone of life" could "pass the word to the matter of things." This shows that the language used by Arguedas, is to translate the Indian legends or to write their literary texts, has an importance as a vehicle for expression of the worldview that emphasizes heterogeneous throughout his work culminating in the experience found in Chimbote.

Keywords: Translation, Anthropology, Latin America.

Ángel Rama en el prólogo a Formación de una cultura indoamericana, un conjunto de ensayos de carácter antropológico de José María Arguedas, enfatiza que el novelista peruano "ha opacado, hasta casi hacerlo desaparecer, al etnólogo" (1975, p. IX). El crítico uruguayo fue también responsable por la recopilación de los textos dispersos. Éste fue un bosquejo debatido y planeado con el intelectual peruano desde 1967, que, según él: “colaboró con interés en el proyecto, sugirió los textos que consideraba más apropiados y llegó a proporcionar algunas copias corregidas." (1975, p. XXV)

La selección idealizada por ambos recoge nueve ensayos, en su mayoría escritos en los años 1950. Rama argumenta que esa década "(...) fue de las más colmadas de su vida intelectual, puesto que en ella, junto con su tarea docente y a sus investigaciones de campo escribió la mayoría del presente volumen y dio a conocer dos obras literarias de alta belleza: Diamantes y pedernales (1954) y Los ríos profundos (1958)." (1975, p. XXVI).

Por el prólogo se entiende que desde por lo menos 1967 la producción literaria y antropológica de Arguedas había llamado la atención del uruguayo. En la década de los 1970 Rama empezó a escribir ensayos acerca de la producción de Arguedas (y más 
específicamente sobre la novela de 58) después recogidos como una obra completa, Transculturación narrativa en América Latina, publicada en 1982 (CUNHA, p. 2007).

El crítico entiende que el peruano tenía un proyecto (1975, pp. XV-XVI) y eso se refleja en el título que él elige para la obra. Para Rama, en la producción de Arguedas no hay escisión; todo lo contrario, habría la "construcción de una tarea intelectual como una totalidad de significación. Esta se vierte a través de una pluralidad de canales, entre los que podemos reconocer al menos tres, para hablar así de José María Arguedas escritor, folklorista, etnólogo" (1975, p. IX).

González-Vigil aclara que fue en el Valle de Mantaro que Arguedas empezó a escribir la obra. En una larga referencia a una entrevista dada por el peruano a Castro-Klarén (1998, p. 69), comenta el origen de la novela:

Concebí Los ríos profundos en una maravillosa comunidad del Valle del Mantaro. Yo la había empezado a escribir como una novela de aventura. Pero seguramente estaba concebida para que tuviera otro desarrollo. Me había matriculado en la Facultad de Educación pero estuve tan enfermo que no pude continuar. Después me volví a matricular para ser antropólogo. Terminé y me enviaron al Valle del Mantaro a hacer un estudio para el Instituto de Estudios Etnológicos. Me habían nombrado jefe de esa sección del Ministerio de Educación. (...) Escribí un capítulo y me sentí tan feliz que empecé a recorrer todo el valle. Era una isla, porque los campesinos lo tratan a uno de igual a igual. Siempre son gente segura de sí misma. Los españoles no se asentaron allí porque el clima no les convenía y porque no había leña. Empecé a escribir con tanto entusiasmo que dejé todo el material antropológico y me puse a escribir Los ríos profundos y no hice nada para el Instituto hasta terminar el libro. Yo me acuerdo que llegó François Bourricaud y le dije: "Estoy escribiendo, no puedo hacer otra cosa". 
La tentativa de escribir la novela habría iniciado entre 1942 y 43. En 48, publicó un adelanto de Los ríos profundos en Las Moradas $^{1}$ (GONZÁLEZ-VIGIL, 1998, p. 71). Sin embargo, todavía serán diez años hasta la primera publicación, lo que correspondería prácticamente a un trabajo de redacción por toda la década de 50. Se concluye que la redactaba concomitantemente a los varios ensayos antropológicos publicados en Formación. Aliado a esa tarea estaba la de recopilador del quechua hablado para el escrito y recopilador y traductor de quechua para español.

Siguiendo lo que teoriza Roman Jakobson (1985), Arguedas realizaría en esos trabajos primeramente una traducción intersemiótica o transmutación, pues pasa relatos orales en quechua para la escrita en quechua, y una traducción interlengual de esa lengua indígena para el español. Acerca de cómo percibía esta su tarea, explicita en el prólogo que antecede El sueño del pongo, Pongoq Mosqoynin, relato oral recogido por él y publicado en 1965, en versión bilingüe, quechua-español (ARGUEDAS, 2009, p. 125): "[h]emos tratado de reproducir lo más fielmente posible la versión original, pero, sin duda, hay mucho de nuestra "propia cosecha' en su texto; y eso tampoco carece de importancia".

Mario Vargas-Llosa también observa esta interrelación en la producción del peruano. Al comentar las traducciones de Arguedas en Canciones y cuentos del pueblo quechua, de 1949, encuentra lo que dice ser "un aire de familia con sus poemas y relatos originales". Para él, esos materiales solo en apariencia serían traducciones, se tratarían de "creaciones con la arcilla de una materia prima ajena" (2004, p. 158). El autor y paisano del antropólogo señala varias reservas acerca de su obra en La utopía arcaica, de 1996, pero considera que:

Esto no desmerece el valor científico de la tarea que Arguedas desarrolló como folclorista, etnólogo y antropólogo; subraya que el artista que había en él estaba también presente en sus trabajos de cateo de las manifestaciones culturales 
del pueblo quechua y los realzaba con una percepción de lo estético, algo infrecuente en ese tipo de estudios. (VARGAS-LLOSA, 2004, p. 158)

Eso no deja de ser lo que entiende Rama (1982) por transculturación narrativa, al tratar de Arguedas y su obra de 1958 como casos ejemplares del proceso descrito por él a partir del concepto creado por Fernando Ortiz (1940) y varios otros aportes teóricos (CUNHA, 2007): la revitalización de una producción literaria por medio de selecciones y recreaciones de los elementos provenientes de otras producciones culturales, fueran ellas de influencia externa o interna a la cultura que se reprocesa. De ese modo una cultura tendría más posibilidades de sobrevivir o tener perpetuadas algunas de sus características según su capacidad de adaptación a los procesos de incrementos y pérdidas de elementos con la cultura en contacto.

Para el uruguayo, llevando la discusión para el ámbito más literario, ese proceso ocurriría en la forma literaria, en la lengua empleada por el autor y en la cosmovisión que ese buscaría preservar en su obra. Esa capacidad de adaptación, que en un primer momento podría parecer una vulnerabilidad, a largo plazo constituiría una ventaja. En eso también cree Arguedas, tanto al concluir que: "[1]as lenguas - como las culturas - poco evolucionadas son más rígidas, y tal rigidez constituye prueba de flaqueza y de riesgo de extinción, como bien lo sabemos." (2009, p. 126) como al revelar en "La novela y el problema de la expresión literaria en el Perú", que buscaba la universalidad al optar por escribir novelas: "¿Fue y es esta búsqueda de la universalidad a través de la lucha por la forma, sólo por la forma? Por la forma en cuanto ella significa conclusión, equilibrio, alcanzado por la necesaria mezcla de elementos que tratan de constituirse en una nueva narrativa." (2009, p. 159).

A partir de lo que notaba como antropólogo, al percibir el distinto modo de reacción de las culturas precolombinas que estuvieron por más tiempo bajo el yugo de los colonizadores y otras que 
pudieron desarrollarse más libremente a pesar del primer contacto temprano con los españoles, él concluye que es imposible detener los cambios y la interrelación entre las culturas. Ese fue el foco de su investigación en Valle de Mantaro. Sin embargo, lo que deseaba, más que como antropólogo, como participante de esa cultura mestiza, era que algunos elementos fueran preservados. Y tal vez se pueda decir que aquellos que él y su generación creían como ideales para sobrevivir a las presiones del capitalismo que se hacía cada vez más presente en Perú.

Así como Rama señala que no hay escisión en la obra de Arguedas, es perceptible su vena de creador en sus trabajos de antropólogos, al recoger relatos orales o al redactar textos de carácter investigativo, como es evidente al final de "Puquio, una cultura en proceso de cambio. La religión local." cuando al contrario de lo que generalmente haría um investigador totalmente vinculado a la cultura occidental, al cuestionarse acerca de la desaparición o cambio de um mito de origen indígeno o mestizo, el intelectual opta por dar voz a la expresión del próprio mito. Con ese procedimiento, lo preserva, en otro medio (el escrito), en otra lengua (la española), para otra cultura (la occidental), y lo perpetua. (CUNHA, 2010, p. 6)

La propia expresión de Arguedas aclara como el investigador y el creador se mesclan en su producción, conformando el intelectual que él fue. En el primer párrafo del fragmento a continuación, se lee el relato objetivo de un antropólogo acerca de su objeto de estudio. En el siguiente, finalizando el ensayo, se presenta la perspectiva de un individuo que se sensilibiza y participa de la cultura que estudia:

Encontramos que la ciudad de Puquio, rápidamente, en 29 años, se ha convertido en un centro comercial de economía activa, de haber sido la capital de una zona agropecuaria anticuada, de tipo predominante colonial. En lo que se refiere a los naturales, observamos que este proceso va encaminan- 
do a la independencia respecto del despotismo tradicional que sobre ellos ejercían y aún ejercen las clases señorial y mestiza; pero, al mismo tiempo, el proceso está descarnando a los naturales de las bases en que se sustenta su cultura tradicional, sin que los elementos que han de sustituirlos aparezcan aún con nitidez. Siguen ahora, aparentemente, un camino abierto hacia el individualismo escéptico, debilitados sus vínculos con los dioses que regularon su conducta social e inspiraron, armoniosamente, sus artes, en las que contemplamos y sentimos una belleza tan perfecta como vigorosa. Inkarrí vuelve, y no podemos menos que sentir temor ante su posible impotencia para ensamblar individualismos quizá irremediablemente desarrollados. Salvo se detenga al Sol, amarrándolo de nuevo, con cinchos de hierro, sobre la cima del Osqonta, modifique a los hombres; que todo es posible tratándose de una criatura tan sabia y resistente. (ARGUEDAS, 1989, pp. 78-79)

Procedimiento semejante es señalado por Cornejo Polar (2008, p. 126) al analizar Los ríos profundos y los episodios de la rebelión de las chicheras y la fuerza de la maza indígena. Habría para el crítico una "fe en el porvenir", una "proyección hacia el futuro", a la vez que el protagonista - Ernesto - "se proyecta hacia el pasado". A partir de esa "doble tensión temporal" se produce un desequilibrio al cual él concluye que "pasado y futuro son incompatibles. Un nuevo desgarrón sacude la obra de Arguedas" (2008, p.127). Lo que Cornejo Polar entiende como desequilibrio, Rama (1982) cree ser un momento de adaptación hacia una nueva etapa. Y como se sabe el camino que tomó la obra literaria de Arguedas y el desenlace trágico de su vida, es difícil entender esa esperanza que el uruguayo señala, sin embargo en la obra de 1958 el desgarre no es tan fuerte y dramático como el de la novela publicada póstumamente, El zorro de arriba y el zorro de abajo.

Mónica Barnabé señala que en 1947 Arguedas en la introducción para la traducción de dos cuentos quechuas alerta que "la particular riqueza del lenguaje oral" (2006, p. 392) quechua solo sería 
captado por medio de la traducción por un lector que hubiera oído hablar desde la niñez el idioma indígena. La crítica concluye que para el peruano "la capacidad de comprensión del lector está supeditada a circunstancias de vida similares a las del traductor."(p. 391). Por lo menos era ese el procedimiento en que él creía en la época. En Los ríos profundos la intención parece ser otra.

Es importante acercarse a la producción literaria de Arguedas y verificar cómo ese procedimiento de traducción y lectura del mundo se presenta. En la novela de 1958, el capítulo "Zumbayllu", según señalan varios críticos ${ }^{2}$, ocupa un lugar importante dentro de la obra, tanto en su aspecto formal como temático. Empieza con una explicación acerca de la formación de la palabra que lo intitula: "La terminación quechua yllu es una onomatopeya. Yllu representa en una de sus formas la música que producen las pequeñas alas en vuelo; música que surge del movimiento de objetos leves. Esta voz tiene semejanza con otra más vasta: illa. (...)" (1998, p. 235).

El lector que leía la historia de Ernesto en el colegio se depara con un título de capítulo que le suena a lengua indígena pero a la cuál probablemente no identifica el significado. Antes de la acción, hay una larga explicación no exactamente sobre qué es el vocablo sino acerca de la formación de la palabra por el sufijo quechua y de otras que por su sonoridad alcanzan la memoria del antropólogo, recuperan objetos de la tradición pre y poshispánica de la cultura indígena. Solo después de ese paseo por la otra cultura el lector es llevado nuevamente a la acción entre los muchachos del colegio.

González-Vigil aclara que ese texto insertado en la novela fue publicado primero como un artículo antropológico intitulado "Acerca del intenso significado de dos voces quechuas" en el periódico La prensa, en 1948, (1998, p. 239). Es interesante que el autor utilice el mismo texto pues demuestra una vez más la interrelación de sus tareas y cómo él ponía mucho de suyo en los textos antropológicos y traducciones y cómo el espíritu investigativo se hacía presente en sus producciones literarias.

Indudablemente, después de leer el texto que intermedia el tí- 
tulo y la exclamación “¡Zumbayllu!” (algunas páginas después con la cual la acción de la novela es retomada) el entendimiento del lector y el sabor acerca de la palabra leída es totalmente distinto. $\mathrm{Si}$ en el título queda la curiosidad acerca del significado de la palabra, después del recurrido al mundo indígena - más que aclarando qué sería el zumbayllu, buscando hacer que su lector entienda por lo menos un poco la construcción de las palabras en quechua, de cómo se forman las imágenes descritas por ella -, podemos decir que el narrador-antropólogo buscó traducir algo de ese mundo a su lector, o según la terminología de Rama (1982), ponerles en contacto con la cosmovisión indígena.

Cuando en un discurso indirecto libre aparece "¡Zumbayllu! En el mes de mayo trajo Antero el primer zumbayllu al Colegio." (1998, p. 239), esa puede ser la exclamación proferida por los muchachos al conocer el objeto llevado por Antero, la del propio narrador Ernesto que en el momento de la escritura, al contar la historia recuerda el objeto y los momentos vividos en el colegio, pero también puede ser la del lector al ver entrar en la acción de la novela el objeto que le fue presentado por el narrador-antropólogo.

El personaje Antero tampoco explica exactamente a los colegas qué es el objeto, él hace que ellos participen del juego. Tanto que narrador-personaje, en otro discurso indirecto libre, recuerda y reproduce, en el ámbito de la escritura, la su curiosidad sentida por Ernesto y sus colegas en el momento de la acción: “¿Qué podía ser el zumbayllu? ¿Qué podía nombrar esta palabra cuya terminación me recordaba bellos y misteriosos objetos?” (1998, p. 240).

El narrador-antropólogo anticipa a la curiosidad del narrador-personaje Ernesto y de los lectores y escribe el largo fragmento haciendo que entremos y participemos de un mundo distinto. El narrador-personaje busca los conocimientos que tiene de las palabras quechuas y del mundo indígena para intentar comprender el objeto. Recurre a su memoria para entender el objeto, así como el narrador-antropólogo nos introdujo en este universo: 
Yo recordaba al gran "Tankayllu”, el danzarín cubierto de espejos, bailando a grandes saltos en el atrio de la iglesia. Recordaba también el verdadero tankayllu, el insecto volador que perseguíamos entre lo arbustos floridos de abril y mayo. Pensaba en los blancos pinkuyllus que había oído tocar en los pueblos del sur. Los pinkuyllus traían a la memoria la voz de los wak'rapukus, iy de qué modo la voz de los pinkuyllus y wak'rapukus es semejante al extenso mugido con que los toros encelados se desafían a través de los montes y los ríos! (1998, p. 240)

También hay indagaciones en el apartado donde el narrador-antropólogo comenta sobre las voces quechuas. Estas toman el carácter un de discurso indirecto libre: “¿Por qué lleva miel en el tapón del vientre? ¿Por qué sus pequeñas y endebles alas mueven el viento hasta agitarlo y cambiarlo? ¿Cómo es que el aire sopla sobre el rostro de quien lo mira cuando pasa el tankayllu?" (ARGUEDAS, 1998, p. 236). El procedimiento demuestra que tampoco el narrador-antropólogo sabe todo, tiene sus dudas, pero como supone que el lector de su novela no conoce ni ese repertorio mínimo nos da el soporte necesario para que adentremos ese mundo. Tal vez este procedimiento venga de la experiencia traumática de Arguedas con la recepción de Yawar Fiesta (1941), criticada hasta mismo por su amigo Manuel Moreno Jimeno a quién él remitía cada capítulo redactado y con la cual perdió un premio literario, según el indigenista Luis E. Valcárcel porque la novela sería ininteligible para quien no hubiera vivido con los indios (VARGAS-LLOSA, 2004, pp. 128-131). A todo eso concluye Cornejo Polar que la novela "puede resentirse por el exceso de información sociológica y antropológica que el texto incluye; sin embargo, su función dentro de la obra íntegra de Arguedas es de primera línea." (2008, p. 124).

En los textos antropológicos de la década de los 1950, en el cuento recogido en 1965 y aun en la novela de 1958, el intelectual opta por hacer un puente entre las tradiciones orales en quechua y 
la cultura escrita en castellano de los "misti" ${ }^{3}$, o sea intenta promover una aproximación, al menos en el ámbito de las letras, de esas dos culturas. Para Rama, él estaría buscando establecer el propio proceso de transculturación narrativa, para Cornejo Polar estaría demostrando una tensión.

El foco del proceso descrito por el crítico uruguayo es la sobrevivencia de una producción literatura al caminar desde un sistema con menos visibilidad hacia uno con más. Si el punto principal del proceso recae en la sobrevivencia de una producción literaria al caminar desde un sistema de menor visibilidad hacia otro de mayor, la traducción representaría, como enfatiza Virgilio Moya, al llevar en consideración las ideas del teórico israelí, un enriquecimiento para el sistema literario que la recibe (MOYA, 2007, p. 138):

(...) se deduce, por parte de Even-Zohar, una visión sistémica de la traducción (o mejor, de las traducciones literarias), parte integrante a su vez del polisistema literario meta (lo que supone una ruptura con los enfoques tradicionales y con el tratamiento individual que le daban a las traducciones), y una enfatización del dinamismo del primer sistema en relación con el segundo y, en consecuencia, con la evolución de su cultura.

Según Thaïs Diniz, la traducción “[d]eixa de ser apenas, como se define tradicionalmente, o transportar, seja de uma língua ou de um sistema, para outro(a) (...) [t]raduzir significa ainda perpetuar ou contestar, aceitar ou desafiar." (1999, p. 42). Si se traza un paralelo del procedimiento de Arguedas a esta amplia concepción acerca de traducción, se puede decir que tanto en sus textos antropológicos, en sus trabajos de recopilación y traducción como en sus obras literarias, el peruano estaría buscando establecer espacio a una cultura que todavía se está configurando a los nuevos cambios. Y, retomando las palabras de Diniz: 
A tradução, portanto, nunca acontece num vácuo onde se pressupõe que as línguas se encontram, mas no contexto da tradição de todas as literaturas, no ponto de encontro entre os tradutores e os escritores, que é cultural. Os tradutores se apresentam, pois como os mediadores entre as tradições literárias, entre culturas, não com o intuito de trazer o original à tona de maneira neutra e objetiva, mas para torná-lo acessível em seus próprios termos. (...) A tradução, pois, não é produzida em perfeitas condições de laboratório, esterilizado e neutro, e sim no entrelugar de várias tradições, culturas e normas. Toda tradução é, portanto, uma tradução cultural. (1999, p. 35)

El propio Arguedas, en el "Primer diario" de El zorro de arriba y el zorro de abajo, declara que es el "tono de vida" que establecía con "todas las cosas" que le hacía "transmitir a la palabra la materia de las cosas”. (1971, p. 7). Si en sus recopilaciones, traducciones y textos antropológicos el peruano busca a la vez preservar el pasado, eso también tiene una influencia en el futuro. Las otras generaciones, los lectores de otras culturas que no la quechua, mestiza o peruana, o hasta se puede decir latinoamericana, tomarán conocimiento de esas historias y mitos por su trabajo, eso es un paso hacia el futuro. En sus novelas, también se nota este movimiento, además de los recuerdos de su niñez, de los elementos de sus investigaciones también hay la expresión de su deseo de cómo podrían ser los hechos.

Para Cornejo-Polar, el esfuerzo de Arguedas se vuelve a "ceñir la palabra a su referente, hacerla transparente e instrumental, permitir que sea como una ventana abierta sobre la realidad" (2008, p. 120). O sea una alternativa dentro de lo que él presenciaba en el mundo que vivía. Lo que para Rama sería la posibilidad harmónica de la transculturación narrativa, para Cornejo Polar era una posibilidad problemática. Tensión que indudablemente es evidente y extremada en la novela finalizada en 1969. 
Roland Forgues, acerca del lenguaje literario de la novela póstuma de Arguedas, dice que ella "ya no logra traducir correctamente la realidad concreta" (1996, p. 310). Sin embargo, el peruano tenía conciencia de esa imposibilidad a lo largo de su amplia producción. Como el propio Arguedas, en 1950, declara: “¡Pero los indios no hablan en ese castellano ni con los de lengua española, ni mucho menos entre ellosi Es una ficción" (2004, p. 159). Otro estudioso de la obra del intelectual peruano, Martin Lienhard sostiene que "[p]ara traducir Chimbote en novela, Arguedas constituyó, como ya se dijo, los principios del vanguardismo urbano occidental en uno de los dos polos del texto" (1996, p. 326).

Para Barnabé algunos escritores entre ellos Arguedas, "desarrollan una estrategia de exilio permanente cuando sus escrituras toman la forma de un acto de traducción” (2006, p. 385). El personaje-narrador y Ernesto, sin duda se sienten forasteros en el espacio del colegio y de Abancay. Así como decía sentirse el serrano Arguedas en Lima. Sin embargo, en esa novela el autor cree en la posibilidad de ser un puente entre la cosmovisión quechua o más próxima a ella y la occidental. La manera que encuentra para eso es promover un paralelismo entre un discurso antropológico, didáctico-ilustrativo - percibido en la descripción del narrador-antropólogo, por ejemplo, - y la acción de la novela - donde él ilustra lo que ya había presentado al lector. Así como, en su ensayo antropológico, paralela a la conclusión racional del investigador hay la expresión del anhelo del hombre que conoce y se identifica con varios puntos da cultura indígena. Nuevamente se concluye que eso para Rama sería la propia transculturación narrativa en curso, para Cornejo Polar representaría una doble tensión que convivían en todas las facetas de Arguedas.

Sin duda, y tal vez el silencio de Rama acerca de la novela publicada póstumamente se deba a eso, en El zorro de arriba y el zorro de abajo lo que tenemos es la ebullición de la tensión encontrada a lo largo de la producción arguediana por Cornejo Polar. El antropólogo y el autor que se mesclan en la obra parece 
que desistieron de intentar traducir la cosmovisión indígena a la cultura occidental. O tal vez se pueda decir que la traducción del mundo mimetiza su caos. Todo se presenta de modo más complejo y caótico: el habla del loco Moncada se contamina a la del enfermo Esteban de la Cruz, la del gringo charanguista Maxwell, la de los serranos que buscan disfrazar que hablan quechua, la de los pescadores, prostitutas y demás personajes explorados o exploradores que pueblan Chimbote así como la de los mitológicos zorros, el de arriba y el de abajo.

\section{Notas}

1. Mónica Barnabé aclara que esa revista dirigida por Adolfo Westphalen entre mayo de 1947 y julio de 49, publicaba tanto autores peruanos de su generación como europeos y por eso "abre el horizonte para un modo diferente de pensar la cultura, el arte y la literatura nacional a partir de un intenso intercambio de ideas y de información con publicaciones europeas norteamericanas y latinoamericanas." (2006, p. 382)

2. Según Renaud Richard la palabra zumbayllu ya constituiría una voz mestiza, pues mesclaría la forma verbal onomatopéyica española "zumba" y onomatopeya quechua "-yllu". (ARGUEDAS, 1998, p. 235). Cornejo Polar realiza un estudio sobre la importancia del capítulo y del objeto en la novela (2008).

3. Arguedas aclara que: "El 'misti' no es el blanco, se designa con ese nombre a los señores de cultura occidental o casi occidental que tradicionalmente desde la colonia, dominaron en la región, política, social y económicamente. Ninguno de ellos es ya, por supuesto, de raza blanca pura ni de cultura occidental pura. Son criollos. Los indios dan a los mestizos el nombre 'mediomisti', o tumpamisti, que tiene la misma significación." (1989, p. 35) 


\section{Bibliografía}

ALCINA FRANCH, J. Mitos y literatura quechua. Madrid: Alianza Editorial, 1989.

ARGUEDAS, J. M. Qepa Wiñaq... Siempre literatura y antropología (prólogo Sybila de Arguedas, edición crítica Dora Sales). Madrid/ Frankfort: Iberoamerica/ Vervuert, 2009. 1998.

. Los ríos profundos (edición de R. González-Vigil). Madrid: Cátedra,

. El zorro de arriba y el zorro de abajo (edición crítica Eve-Marie Fell). Madrid/ Paris/ México/ Buenos Aires/ São Paulo/ Rio de Janeiro/ Lima: ALLCA XX, 1996.

. Formación de una cultura nacional indoamericana (Selección y prólogo Ángel Rama). Ciudad de México: Siglo XXI editores, 1975.

BARNABÉ, M. "José María Arguedas traductor". In: José María Arguedas: hacia una poética migrantes (editor Sergio Franco). Pittsburg: Instituto Internacional de Literatura Iberoamericana, 2006, pp. 379-396.

CORNEJO POLAR, A. "Un ensayo sobre Los zorros de Arguedas". In: El zorro de arriba y el zorro de abajo (edición crítica Eve-Marie Fell). Madrid/ Paris/ México/ Buenos Aires/ São Paulo/ Rio de Janeiro/ Lima: ALLCA XX, 1996, pp.296-306.

CORNEJO POLAR, A. La novela peruana. Lima: Centro de Estudios Literarios Antonio Cornejo Polar, 2008.

CUNHA, R. B. Transculturação narrativa: seu percurso na obra crítica de Ángel Rama. São Paulo: Humanitas/FAPESP, 2007. 
. "Entre huayronqos e ayawantus: o ciclo de vida e morte no projeto literário de José María Arguedas”. In: Revista Criação \& Crítica, 2010, p. 1-17.

DINIZ, T. F. N. "O conceito de tradução". In: Literatura e Cinema: da semiótica à tradução, Ouro Preto: Editora UFOP, 1999, p. 25-42.

FRANCO, S. R. "Entre la abyección y el deseo: para una relectura de $E l$ sueño del pongo." . In: José María Arguedas: hacia una poética migrantes (editor Sergio Franco). Pittsburg: Instituto Internacional de Literatura Iberoamericana, 2006, p. 311-329.

FORGUES, R. "Por qué bailan los zorros" en El zorro de arriba y el zorro de abajo (edición crítica Eve-Marie Fell). Madrid/ Paris/ México/ Buenos Aires/ São Paulo/ Rio de Janeiro/ Lima: ALLCA XX, 1996, p. 307-315.

JAKOBSON, R. Linguística e comunicação. São Paulo: Cultrix, 1985.

LIENHARD, M. "La 'andinización' del vanguardismo urbano". In: El zorro de arriba y el zorro de abajo (edición crítica Eve-Marie Fell). Madrid/ Paris/ México/ Buenos Aires/ São Paulo/ Rio de Janeiro/ Lima: ALLCA XX, 1996, p. 321-332.

MOYA, V. La selva de la traducción - teorías traductológicas contemporáneas. Madrid: Cátedra, 2007.

RAMA, Á. Transculturación narrativa en América Latina. Montevideo: Fundación Ángel Rama, 1982.

VARGAS-LLOSA, M. La utopía arcaica - José María Arguedas y las ficciones del indigenismo. México D.F.: Fondo de Cultura Económico, 2004.

Recebido em 30/08/2012

Aceito 30/10/2012 